\title{
Biamperometric Applications to Antioxidant Content and Total Antioxidant Capacity Assessment: An Editorial
}

\section{Aurelia Magdalena Pisoschi*}

University of Agronomic Sciences and Veterinary Medicine of Bucharest, Faculty of Veterinary Medicine, Bucharest, Romania

Oxidative stress can be regarded as the lack of balance between the reactive oxygen/nitrogen species (hydrogen peroxide $\mathrm{H}_{2} \mathrm{O}_{2}$, superoxide radical anion $\mathrm{O}_{2}^{-}$, singlet oxygen $\mathrm{O}_{2}$, hydroxyl radical HO., hydroperoxyl radical $\mathrm{HO}_{2} \cdot$, hypochlorous acid $\mathrm{HOCl}$, nitric oxide NO, peroxynitrite ONOO-) production and the organism's defense ability exerted by the antioxidant system [1]. Reactive oxygen species can promote structure alterations in all classes of biomolecules. Lipids are the most prone to oxidation: polyunsaturated fatty acids oxidation implies formation of carbonylated final products, such as malonyl dialdehyde and 4-hydroxynonenal. The backbone and the side chain of proteins can be attacked by reactive oxygen species, and alteration in purine and pyridine bases structure results in DNA mutations [2]. Moreover, oxidative stress has been viewed as more complex than mere radical overproduction, being reconsidered as a perturbation of redox signaling pathways in the cell [3-5].

The intake of plant-sourced antioxidants contained in fruits and vegetables leads to lowering oxidative stress-related pathology, and this fact has been confirmed by epidemiological studies, hence the interest in applying performant methodologies to assess the total antioxidant capacity as quality index of foodstuffs [6].

The application of electrochemical techniques in antioxidant and antioxidant capacity determination is characterized by sensitivity, fastness, simple and relatively unexpensive instrumentation, small volumes of samples, with improvement of research resources use. The analytical signal does not depend on the distance that radiation travels in the analytical cell or on the turbidity, and the dynamic range is large [7-12].

The biamperometric method relies on recording the current intensity between two identical working electrodes at a small potential difference, and found in a solution where a reversible redox couple is present. The analyte reacts with the indicating redox couple $\left(\mathrm{Fe}^{3+} \mathrm{Fe}^{2+}\right.$, $\left.\mathrm{I}_{2} / \mathrm{I}^{-}, \mathrm{Fe}(\mathrm{CN})_{6}{ }^{3-} / \mathrm{Fe}(\mathrm{CN})_{6}^{4-}\right)$, the selectivity of the technique depending on the specificity of the reaction involving the oxidized form of the redox pair and the antioxidant. In DPPH./DPPH biamperometry, antioxidants react with DPPH. (radical form) decreasing its concentration, and generating DPPH (reduced form). When employed working conditions are as such, for the radical form concentration to be smaller than one proper to the molecular form, cathodic current is limited by the lower concentration of DPPH. radical in the indicating mixture $[13,14]$.

$\mathrm{DPPH} \bullet / \mathrm{DPPH}$ biamperometry was employed in the analysis of fruit juices for their total antioxidant capacity, using two identical Pt electrodes [13] and also tea, wine and coffee using glassy carbon electrodes [14]. The most significant values of the total antioxidant capacity were proper to juices freshly obtained from fruits, namely 9.07 $\mathrm{mM}$ Trolox for orange juice and 6.25 mM Trolox for lemon juice [13]. $\mathrm{ABTS}^{+} / \mathrm{ABTS}$ is a redox pair also extensively applied to biamperometric antioxidant capacity evaluation. A peroxidase-relying flow system was responsible for the cation radical formation, enabling analysis of juices, tea and wine using interdigitated microelectrodes [15]. $\mathrm{ABTS}^{+\cdot}$ was also obtained by glucose oxidase - peroxidase, for the analysis of wine and spirits with excellent sensitivity, $0.165 \mathrm{nA} / \mu \mathrm{M}$ Trolox [16].
Samples of Brazilian woods, cabreuva (Myrocarpus frondosus), cabreuvavermelha (Myroxylon balsamum), imbuia (Octea porosa) and pequi (Caryocar brasiliense), and oak (Quercus sp.) extracts were subject to ceric reducing antioxidant capacity (CRAC) analysis, relying on $\mathrm{Ce}^{4+} / \mathrm{Ce}^{3+}$ redox couple. Chronoamperometric determinations enabled quantification of the decrease of $\mathrm{Ce}^{4+}$ concentration, that was caused by its reduction by antioxidants present in the sample. The $\mathrm{Ce}^{4+} / \mathrm{Ce}^{3+}$ redox pair being characterized by an elevated value of the redox potential, it allows determinations at a boron-doped diamond film electrode, with results given as Trolox equivalents, that illustrated the variation of the antioxidant activity of analysed extracts: oak (1.73) $>$ cabreuva-vermelha $(1.05)>$ cabreuva $(0.90)>$ imbuia $(0.71)>$ pequi (0.31) [17].

The ceric reducing antioxidant capacity assay was also exploited by virtue of its direct electron transfer facility, for determining the antioxidant capacity of eight antioxidant compounds, also based on the capacity to reduce the oxidized form of the redox couple [18]. The developed technique was based on observing the decrease of the $\mathrm{Ce}^{4+}$ concentration after its reaction with tested antioxidants. The current intensity decreased in time after imposing the due potential step, and this was described by Cottrell law. The following trend of variation of antioxidant capacities resulted from this comparative investigation that relied on chronoamperometric measurements: tannic acid $>$ quercetin $>$ rutin $>$ gallic acid $\approx$ catechin $>$ ascorbic acid $>$ butylated hydroxyanisole $>$ Trolox. The results were consistent with those furnished by previous studies, and by the applied conventional FRAP assay [18].

Biamperometry integrated in a flow injection analysis (FIA) setup was also applied to antioxidant assessment. This technique involves the valve injection of a liquid sample, in an inert, unsegmented carrier flow. Peristaltic pumps are responsible for the transport of the sample and reagents and the detection is ensured, at the end of the experimental setup, by various methods: photometric, electrochemical, mass spectrometrical $[19,20]$. Vitamin C assessment relied on the oxidation of the analyte at acidic $\mathrm{pH}$, by $\mathrm{I}_{2} / \mathrm{I}^{-}$employed as oxidizing agent. The biamperometric detection of the amount of iodine consumed, allowed for the assessment of vitamin $\mathrm{C}$ with a linear range of analytical response comprised between $5 \times 10^{-5}$ and $5 \times 10^{-4} \mathrm{M}$, a $1.08 \% \operatorname{RSD}(\mathrm{n}=10$; $\left.\mathrm{c}=2.5 \times 10^{-4} \mathrm{M}\right)$ and high throughput of 60 samples $^{-1}[21]$.

*Corresponding author: Aurelia Magdalena Pisoschi, University of Agronomic Sciences and Veterinary Medicine of Bucharest, Faculty of Veterinary Medicine, Bucharest, Romania, Tel: +40 21318 2266; E-mail: aureliamagdalenapisoschi@yahoo.ro

Received: October 05, 2015; Accepted: October 28, 2015; Published October 31, 2015

Citation: Pisoschi AM (2015) Biamperometric Applications to Antioxidant Content and Total Antioxidant Capacity Assessment: An Editorial. Biochem Anal Biochem 4: 218. doi:10.4172/2161-1009.1000218

Copyright: () 2015 Pisoschi AM. This is an open-access article distributed under the terms of the Creative Commons Attribution License, which permits unrestricted use, distribution, and reproduction in any medium, provided the original author and source are credited. 
Citation: Pisoschi AM (2015) Biamperometric Applications to Antioxidant Content and Total Antioxidant Capacity Assessment: An Editorial. Biochem Anal Biochem 4: 218. doi:10.4172/2161-1009.1000218

Page 2 of 2

It can be concluded that, with a rigorous control of the operational parameters such as the molar ratio between the oxidized and the reduced form of the redox couple, and the potential value applied, biamperometry can constitute a viable method in antioxidant content and total antioxidant capacity determination in foodstuffs.

\section{References}

1. Persson T, Popescu BO, Cedazo-Minguez A (2014) Oxidative stress in Alzheimer's disease: why did antioxidant therapy fail? Oxid Med Cell Longev 2014: 427318.

2. Gandhi S, Abramov AY (2012) Mechanism of oxidative stress in neurodegeneration. Oxid Med Cell Longev 2012: 428010.

3. López-Alarcóna C, Denicola A (2013) Evaluating the antioxidant capacity of natural products: A review on chemical and cellular-based assays. Anal Chim Acta 763: 1-10.

4. Jones DP (2006) Redefining oxidative stress. Antioxid Redox Signal 8: 18651879.

5. Finley JW, Kong AN, Hintze KJ, Jeffery EH, Ji LL, et al. (2011) Antioxidants in foods: state of the science important to the food industry. J Agric Food Chem 59: $6837-6846$

6. Kasote DM, Katyare SS, Hegde V, Bae H (2015) Significance of antioxidant potential of plants and its relevance to therapeutic applications. Int J Biol Sci 11: 982-991.

7. Svork L (2013) Determination of caffeine: a comprehensive review on electrochemical methods. Int J Electrochem Sci 8: 5755-5773.

8. Pisoschi AM, Negulescu GhP, Pisoschi A (2010) Ascorbic acid determination by an amperometric ascorbate oxidase-based biosensor. Rev Chim (Bucharest) 61: 339-344.

9. Pisoschi AM, Pop A, Negulescu GhP, Pisoschi A (2011) Determination of ascorbic acid content of some fruit juices and wine by voltammetry performed at Pt and Carbon Paste Electrodes. Molecules 16: 1349-1365.

10. De Lima AA, Sussuchi EM, de Giovani WF (2007) Electrochemical and antioxidant properties of anthocyanins and anthocyanidins. Croat Chem Acta 80: 29-34

11. Pisoschi AM, Danet AF, Kalinowski S (2008) Ascorbic acid determination in commercial fruit juice samples by cyclic voltammetry. J Autom Methods Manag Chem 2008: 8

12. Pisoschi AM, Cimpeanu C, Predoi G (2015) Electrochemical methods for tota antioxidant capacity and its main contributors determination: A review. Open Chem 13: 824-856.

13. Pisoschi AM, Cheregi MC, Danet AF (2009) Total antioxidant capacity of some commercial fruit juices: electrochemical and spectrophotometrical approaches. Molecules 14: 480-493.

14. Milardovic S, Ivekovic D, Rumenjak V, Grabaric BS (2005) Use of DPPH・ I DPPH redox couple for biamperometric determination of antioxidant activity. Electroanalysis 17: 1847-1853.

15. Milardovic S, Kerekovic I, Derrico R, Rumenjak V (2007) A novel method for flow injection analysis of total antioxidant capacity using enzymatically produced $\mathrm{ABTS} \cdot+$ and biamperometric detector containing interdigitated electrode. Talanta 71: 213-220.

16. Milardovic S, Kerekovic I, Rumenjak V (2007) A flow injection biamperometric method for determination of total antioxidant capacity of alcoholic beverages using bienzymatically produced ABTS+?. Food Chem 105: 1688-1694.

17. de Queiroz Ferreira R, Avaca LA (2009) Electrochemical determination of the antioxidant capacity of Brazilian woods as alternative materials for the aging of cachaça. Braz J Food Technol VII BMCFB: 27-33.

18. De Queiroz Ferreira R, Avaca LA (2008) Electrochemical determination of the antioxidant capacity: the ceric reducing/antioxidant capacity (CRAC) assay. Electroanalysis 20: 1323-1329.

19. Ranger CB (1981) Flow injection analysis. Principles, techniques, applications, design. Anal Chem 53: 20-32.

20. Danet AF (1995) Instrumental methods of chemical analysis, Scientific Edition, Bucharest.

21. Cheregi M, Danet AF (1997) Flow injection determination of I-ascorbic acid in natural juice with biamperometric detection. Anal Lett 30: 2625-2640. 